\title{
Description of the semantic potential of the si-construction in Basse Mandinka
}

\author{
Alexander Andrason \\ Department of Ancient Studies, Stellenbosch University, Private Bag X1, 7602 Matieland, South Africa \\ E-mail: andrason@sun.ac.za
}

\begin{abstract}
The present paper provides a detailed description of the semantic potential offered by the si-construction in Basse Mandinka (a regional variety of the Gambian Mandinka language), by enumerating all temporal, aspectual, taxis and modal values which this verbal form may convey. The study demonstrates that the si-construction offers a wide range of senses. Most commonly, the construction introduces the idea of futurity, regularly accompanied by modal tones of necessity and obligation. More specifically, in the first person, it expresses desires and promises, obligation and necessity, as well as, permission and deliberation; in the second person, it functions as an imperative; and in the third person, it approximates the category of a jussive. The si-construction also introduces modal ideas of obligation and necessity situated in a past time frame, being additionally able to function as a future in the past category. The si-construction can likewise convey the sense of epistemic possibility with no evident future undertones. Finally, it can denote present habitual and customary activities. A profoundly modal nature of the $s i$-construction additionally justifies its common use with the verb noo "be able, can". In such cases, it introduces various modal nuances, typically bereaved of any future sense.
\end{abstract}

Keywords: African linguistics; Mande family; Mandinka; verbal system; lexical semantics

\section{Introduction}

Mandinka - one of the languages spoken in Gambia ${ }^{1}$ and other West African countries together with Bambara, Maninka, Dyula or Jaahanka, forms the Manding group: a moderately mutually intelligible collection of dialects or languages. Manding, itself, constitutes a part of the Western branch of the Mande family (Kastenholz 1996:281; Vydrine, Bergman and Benjamin 2000; and Williamson and Blench 2000), which in turn is classified as a member of the Niger-Kongo linguistic realm.

In Gambia alone, Mandinka is spoken by roughly half a million native speakers. This language is, however, the mother tongue of approximately $1,350,000$ people given that it is also widely spoken in Senegal $(669,000)$ and Guinea Bissau $(167,000){ }^{2}$

\footnotetext{
${ }^{1}$ In this paper, Gambian Mandinka is in focus because, as will be explained below, the evidence has been collected in the Eastern part of this country.

${ }^{2}$ The figures correspond to the situation from 2006 (Lewis 2009)
} 
The Mandinka variety which will be discussed in the present paper corresponds to a vernacular spoken in the easternmost part of the country, more specifically, in the capital city of the Upper River Region, Basse and in the following neighboring villages: Manneh Kunda, Mansajang, Kaba Kama and Bassending (hereafter, this tongue will be referred to as "Basse Mandinka"). Although profoundly similar to the language which could be labeled as "Standard Mandinka" (a normalised and standardised version of Gambian Mandinka employed in dictionaries, ${ }^{3}$ grammars and teaching books, ${ }^{4}$ in translations of important works of Christian and Islamic literature ${ }^{5}$ and in television or on the Internet), the regional variation employed in Basse shows certain peculiarities. For example, the voiced velar stop [g], absent in Standard Mandinka, is extensively used, functioning furthermore as an authentic phoneme. Likewise, in Basse Mandinka, one can form possessive or pronominal constructions employing the postposition $y e$, a technique nonexistent in the normalised language which regularly uses the entity $l a .^{6}$

Despite some extensive descriptions of the Mandinka grammar - in particular Rowlands (1959) and Creissels (1983) - and several papers, various areas of the linguistic organisation of the language still require a more systematic examination. One such area is the need for a comprehensive monographic analysis of the semantic properties of the si-construction. The siconstruction is a verbal analytic category formed by combination of the auxiliary si (or its variant $s e$ ) and the main verb (or its base) as illustrated in (1) below:

$$
\begin{aligned}
& \text { I si } \mathbf{s i}^{7} \text { ke! } \\
& \text { you } \mathrm{SI}^{8} \text { it do } \\
& \text { "You will do it!" }
\end{aligned}
$$

This construction has been discussed in some descriptive grammars (e.g. Macbrair 1842; Rowlands 1959; Creissels 1983; and Gamble 1987) and mentioned briefly in articles where other linguistic issues have been the main focus.

For example, Macbrair (1842:18) classifies the $s i$-construction as a "first" future category, one that expresses future time definitively. He notes, however, that this future meaning may be modified by means of certain words which accompany the construction. Specifically, when the $s i$-construction is employed with the particle $f_{o}$, it results in an obligatory meaning. Consider, for example, Fo n si a kanu "I should love him" (Macbrair 1842:20). Likewise, with the verb noo, the construction conveys a modal idea of possibility and ability, as in N si taa noo "I can go" (Macbrair 1842:20).

\footnotetext{
${ }^{3}$ For instance, Mandinka English Dictionary (1988) and (1995).

${ }^{4}$ See A practical orthography of Gambian Mandinka (1988) and (1993) and Mandinka Learning Manual (2002).

${ }^{5}$ For example, Kambey Kutoo "New Testament" (1988), Kambey Kotoo "Old Testament" (1998) or Selections from the Writings of the Promised Messiah (1988).

${ }^{6}$ Despite a number of distinctive traits, it may not be accurate to consider the Basse variety a dialect of Standard Mandinka: The differences are mostly phonetic and lexical. On the other hand, it is obvious that the classification of a given linguistic organisation as a dialect - or as a language - is not solely a linguistic issue, but rather is conditioned by several political, sociological and economic factors. Furthermore, it should be observed that some of the mentioned dissimilarities are not restricted to the Basse area but, quite the reverse, can be found in other parts of Gambia. For a more comprehensive examination of the differences between Basse Mandinka and Standard Mandinka, see Andrason (forthcoming (a)).

${ }^{7}$ The relevant forms of the $s i$-construction will be given in bold type.

${ }^{8}$ All markers of the $s i$-construction - either $s i$ or $s e-$ will be glossed as SI.
} 
Creissels (1983) defines the $s i$-construction as an expression of eventuality: it denotes events which could and/or should occur. In his view, the construction offers two main sorts of meaning, derivable from the "eventual" domain: (i) it introduces oblique commands or suggestions (cf. also Mandinka Learning Manual 2002:11 on the classification of the construction as an indirect imperative) and (ii) it denotes futurity, probability and potentiality. Gamble (1987:20) discerns from the construction an emphatic future, corresponding to the English periphrases formed with the verbs must and should. He also observes that, in the second person, the construction can function as a "mild" imperative. Colley (1995:14) proposes that the si-construction is an imperative, e.g., I si naa saama! "You come tomorrow!" or Ali si naa saama! "You all come tomorrow!". Following Macbrair (1842), he notes, however, that the construction may commonly be found with the auxiliary verb noo or the particle fo, providing meanings of possibility ( $N$ si taa noo "I can go" and Ali si seyi noo saayiy "You can go back now"; Colley 1995:14) and obligation/necessity (May kendeyaa fo $n$ si taa lopitaanoo to "I am not well, I must go to hospital"), respectively. Finally, Creissels (1983) and Wilson (2000:114) emphasise that the si-construction can also introduce a routine when described in stages: Niy fiyiroo banta moolu si buindewo dati "When the sowing is over, people (will) start the weeding". This use harmonises with the habitual function of the si auxiliary in other dialects (Wilson 2000:114). ${ }^{9}$

This paper aims to fill a gap in the provided literature by meeting the abovementioned necessity for a detailed study of the si-construction. It provides a thorough description of this construction's semantic potential, in accordance with the usage detected in the capital of the Upper River Region and its vicinity, i.e., in Basse Mandinka. More concretely, the article enumerates all possible specific values - the temporal, aspectual, taxis and modal - which the $s i$-construction may convey. In other words, this paper determines all possible contexts within which the si-construction occurs and examines the sense this construction expresses in each such environment by taking a clearly descriptive focus. ${ }^{10}$ This means that the sense of a grammatical form is understood as its compatibility within a given context.

A usage-based and cognitive approach to lexical semantics views the meaning of a grammatical form as its entire semantic potential, i.e. as a set-theoretical union of senses that this form may convey in any range of potential situations. Each one of these senses clearly arises due to contextual factors. More specifically, each sense is a compositional outcome of the verbal form itself and the semantic, syntactic and/or pragmatic environment in which it appears. As a result, the form's semantic potential (its entire polysemy or collection of individual senses) is likewise a contextual phenomenon (Evans and Green 2006:352-53, 368; Nikiforidou 2009:17, 26; and Bybee 2010:183-193).

When decomposing the meaning of the si-construction into specific senses - and thus when showing its usage in determined context in which a given value is activated - the author will make use of standard semantic domains employed in typological and grammaticalisation studies, e.g. habituality, durativity, present and futurity (cf. Bybee, Perkins and Pagliuca 1994;

\footnotetext{
${ }^{9}$ It should be noted that all of the studies mentioned above have dealt with the $s i$-construction in the variety which has been labeled as Standard Mandinka. Finally, in this brief survey, one may also quote Drammé (2003:46-47) who, similarly to the above mentioned scholars, equals the si-construction with a future and imperative, both direct and oblique.

${ }^{10}$ All the examples quoted in the present paper - collected during field trips and research carried out by the author in the Upper River Region in Gambia in 2010 and 2011 - have been provided by ten native Mandinka speakers residing in Basse or in villages located in its vicinity.
} 
and Dahl 2000). Especially abundant will be modal domains and values. Most of them follow the labels employed by Bybee et al. (1994) although distinctions, proposed by Palmer (1986), Portner (2009) and Depraetere and Reed (2011), will also be used. As the sphere of agentoriented and speaker-oriented modality are concerned, the following values will be distinguished: physical ability or mental capacity (Bybee et al. 1994:187-194, 319), obligation, imperative and jussive (orders, commands and necessity; Bybee et al. 1994:177, 179, 181, 320 321; and Palmer 1986:23-24), volition (desires and promises; Bybee et al. 1994:178, 320), permission (Bybee et al. 1994:19, 320) and deliberation (Palmer 1986:40, 111). Furthermore, the senses of root possibility, epistemic possibility and probability will be differentiated (Bybee et al. 1994:197-210, 320-321; and Depraetere and Reed 2011:3-4, 269-290) and so will the value of a modal future (Bybee et al. 1994:279-280). Additionally, the concept of a subjunctive (i.e. a syntactically determined or subordinating mood with its prototypical final and purposive uses) will be employed (Bybee et al. 1994:212-230, 321-322). Finally, as far as the conditional periods are involved, the values of real factuality, real counterfactuality ("hypotheticality") and unreal counterfactuality will be distinguished (Bybee et al. 1994:236-238, 322-323).

\section{Data}

In order to impose some order on an extensive range of meanings displayed by the siconstruction, this study will be divided into four sections which correspond to four distinct syntactic environments. First, uses in main clauses - including those cases in which the construction is complemented by the modal particle $f_{0}$ - will be described. Second, the author will present values provided by the $s i$-construction in cases where it appears in main clauses and is accompanied by the verb noo "can, be able, may". Third, the reader will be familiarised with senses found in temporal and conditional apodoses. And fourth, semantic properties displayed in subordinate clauses - both asyndetic (i.e., introduced without any overt conjunction) and syndetic (i.e., connected by a conjunction) - will be explained.

\subsection{Main clauses}

In main clauses, ${ }^{11}$ the $s i$-construction quite commonly expresses future events accompanied by a strong modal undertone of obligation or compulsion. Consequently, when used with the second person singular or plural pronoun, it is employed with a force comparable to that of an imperative:
a. I si a konton!
you SI him greet
"You will greet him! / You must greet him! / Greet him!"
b. I si moto doo say!
you SI car another buy
"You will buy another car! / You must buy another car! / Buy another car!"
c. I si a ke!
you SI it do
"You will do it! / You must do it! / Do it!"

\footnotetext{
${ }^{11}$ All main clauses which can be interpreted as asyndetically subordinated are excluded from the discussion in this section (cf. section 2.4 below).
} 
d. Saayin i si dalasi tay joo

now you SI dalisi ten pay

"Now, you will pay 10 dalasis! / Now, you must pay 10 dalasis! / Now, pay 10 dalasis!"

This sense of obligation or order is clearly visible in cases where the si-construction is followed by the ye-construction. ${ }^{12}$ The ye-construction, when preceded by an overt imperative form and directed to the second person singular or plural, regularly expresses commands or suggestions addressed to a single interlocutor or to a group of persons. Thus, it provides the same meaning of necessity and constraint as the imperative itself (cf. (3), quoted following Andrason forthcoming (b)):

\section{Wuli, i ye loo ì teema! \\ stand.up you YE stand we among \\ "Arise and stand here in the middle of us!"}

As explained above, orders are commonly introduced in Mandinka by means of the siconstruction. Hence, it is not surprising that the si-construction is commonly followed by the $y e$-construction with the sense of an imperative. In such cases, the si-construction displays a value analogous to the use where the ye-construction is introduced by an overt imperative category. Consequently, the fact that the si-construction and the imperative produce an identical impact on the ye-construction - i.e. they impose its interpretation as an imperative demonstrates that the si-construction must exhibit a sense profoundly similar to that which is conveyed by the explicit imperative proper form.

Ali si a samba nay, ali ye a faa!

you SI him bring to.here you YE him kill

"Bring him here and kill him!"

The idea of a command may be strengthened and made explicit by means of the particle $f_{0} .^{13}$ Compare the two following sentences: while the former (5a) portrays a future event as an obligation, the latter $(5 b)$ emphasises the necessity of the action leaving the temporal connotations (i.e. futurity of the activity) in the second plan:
a. I si a safee!
you SI it write
"You will write it! / You must write it! / Write it!"
b. Fo i si a safee!
OBL you SI it write
"You must write it! / you have to write it!"

When the $s i$-construction is used with the first person singular or plural, it again indicates future activities but, this time, coloured by a modal shade of volition and promise:

\footnotetext{
12 The $Y E$-construction is formed by means of the entity ye (or its variants in the first person singular and plural: $\eta a, n a$, ne, etc.), e.g. a ke "to do" > a ye a ke. The lexeme ye will be glossed "YE" in examples 3 and 4.

${ }^{13}$ In this function, the particle fo will be glossed OBL (i.e. "obligation").
} 
(6)
a. Nsi a ke!
I SI it do
"[I promise,] I will do it!"
b. $\quad$ s sekolomandiyo bondi $k a b^{14} i$ ña kono
I SI straw (small stick) take.out from your eye inside
"I will take out [I offer myself] the speck that is in your eye"
c. N si naa!
I SI come
"[I promise,] I will come!"

Nevertheless, the si-construction employed in the first person singular and plural may also indicate orders and necessity. In that case, it is most commonly introduced by the particle $f o$. This means that if one wishes to emphasise the idea of obligation - and conversely minimise temporal connotation (i.e. the future tense value) and disregard or eliminate volitional connotations - then one quite regularly employs the particle fo:

\author{
Fo n si muru nay \\ OBL I SI return to.here \\ "I must come back / I have to come back"
}

Additionally, when a sentence that includes the si-construction in the first person singular or plural constitutes a question, the sense of the entire expression is analogous to a mood of permission (8a) or deliberation $(8 b)$ :
a. Fo n se duy jay?
whether I SI enter here
"May I come in?"
b. M may kendeyaa. Fo n si taa lopitaanoo to?
I not be.healthy. whether I SI go hospital to
"I am not well. Should I go to the hospital?"

The si-construction may likewise be addressed to the third person singular and plural with a value of future necessity and obligation - comparable to the sense which is available in the remaining persons -, conveying strong orders, commands and instructions.
a. A si a ke!
he SI it do
"He will do it! / He must do it!"
b. A si naa!
he SI come
"He will come! / He must come!"
c. $\quad$ Kayroo si tara duniyaa moolu kono
peace SI be world people in
"May peace be on earth among the people"

Yet again, the nuance of obligation may be emphasised and made explicit if one employs the particle $f o$. In this manner, the $s i$-construction approximates the category of a jussive:

${ }^{14}$ The slot $k a$ bo means "from". 
Fo a si a ke!

OBL he SI it do

"He must do it! / He has to do it!"

It must be noted that the modal value of necessity and compulsion may likewise appear in a past time frame, corresponding to English expressions such as had to or should:
a. İ si muru nay
They SI return to.here
"They had to / they should [at that time, they were compelled to] return"
b. I si a la yaamaroolu niy luwaalu muta
they SI he of ${ }^{15}$ commandments and statutes accept
"They had to / should [at that time, they were compelled to] keep his commandments and statutes"

In other examples found with a past reference, the $s i$-construction approximates the category of a future in the past, such as the English expression he was going to do or the Spanish locution iba a hacer, although a properly modal interpretation (should, ought, could) is also possible (cf. also examples (23) and (28b) which express past possibility, probability and necessity, corresponding to would have done or should have done in English):

$$
\begin{aligned}
& \text { Bituy Menahemu ye kodoo dii a la, niy kamma la a si a maakoyi ka... } \\
& \text { then Menahem did silver give him at/with, this because at/with he SI him help } \\
& \text { so.that... } \\
& \text { "Then Menahem gave him the silver; because of this he was going to help him } \\
& \text { to... / he ought to help him to..." }
\end{aligned}
$$

As far as modal properties are concerned, it shall be observed that in certain instances, the only value available - or relevant - is the sense of epistemic possibility. Conversely in such cases, the temporal meaning of a future is eliminated:

$$
\begin{array}{ll}
\text { a. } & \text { A si ke } \\
\text { it SI happen } \\
\text { "It may happen / Maybe" } \\
\text { b. } \quad \text { A si bey } \\
\text { it SI agree } \\
\text { "It may be possible" }
\end{array}
$$

In addition to future and modal values introduced thus far, one may detect another - although rather infrequent - use of the si-construction, namely, this construction may display a force that is similar to the value which is offered by the $(b u) k a$ construction: It expresses habitual durative general activities. This sense can be clearly observed in the following sentence where the siand $(b u) k a$ constructions occur jointly and both convey the meaning of a habitual general or simple present:

${ }^{15}$ The sequence a la (literally "he of") equals the English possessive pronouns of the third person singular "his". 
(14) a. İ buka sila Alla la sako ì si a la karandiroolu niy a la kumoolu muta they do.not fear God at/with nor they SI he of instructions and he of words accept

"They do not fear the God, nor do they follow his instructions or his ordinances"

b. A may a je sako a sia loy

he did.not it see or he SI it know

"He neither sees him nor knows him"

\subsection{Main clause - accompanied by the verb noo}

Given the profoundly modal character of the si-construction, it is not surprising that it frequently appears in the company of an explicitly modal verb noo "can, may, be able, know how to". It should be noted that in such cases, the future sense of the si-construction is significantly weakened and the sole relevant value corresponds to modality.

In various instances, the si+noo construction expresses agentive modal senses related to physical ability or mental capacity, thus indicating that the subject can perform a given action because he or she is able to do it or knows how to do it.
a. $\quad$ s se motoo borindi noo
I SI car drive can
"I can drive a car / I know how to drive a car"
b. Jumaa le si junuboolu yamfa noo Alla koolaa? who $\mathrm{EMPH}^{16}$ SI sins forgive can God except
"Who but God can (is able) forgive sins?"
c. N si a ke noo
I SI it do can
"I can (am able to) do it"

No less common is the value of root possibility, a modal meaning that is closely related to the concept of ability (Depraetere and Reed 2011:4). The domain of root modality is concerned with the possibility of the actualisation of situations (Depraetere and Reed 2006:269-290). In these cases, the speaker does not pronounce himself on the likelihood of a given situation and its actualisation (cf. epistemic modal sense below) or on his/her mental and physical capacity (cf. examples quoted above), but rather merely states whether there is a possibility of performing an event (cf. the example provided by Depraetere and Reed 2011:3, namely You can find the details on the Internet).
a. I si a tara noo bitikoo to you SI it find can shop at "You can find it at the shop"
b. $\quad$ si i kuu noo araba-wo-araba
I SI them wash can Wednesday-and-Wednesday
"I can wash them every Wednesday"

\footnotetext{
${ }^{16}$ The lexeme $l e$ (or $n e$ ) is an emphatic particle that will hereafter be glossed as EMPH.
} 
The si-construction can also convey the idea of epistemic possibility. In such instances, the speaker indicates that a given proposition is possibly true in terms of probability or verisimilitude, cf. You may be wrong or It may rain (Depraetere and Reed 2011:3):

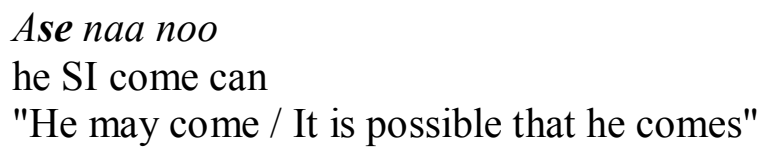

Likewise, the idea of permission is commonly expressed by the periphrasis composed by the auxiliary si and the verb noo:
a. Fo n se taa noo? whether I SI go can "May I go?"
b. Fo n si a soto noo? whether I SI it have can "May I have it?"
c. I si taa noo saayin! you SI go can now "You may go now!"

Finally, the verb noo in the si-construction may express certain volitional nuances of daring:

Ite si a fo noo ñadi le ko you SI it say can how EMPH that "How can you (dare you) say that ..."

\subsection{Conditional and temporal apodoses}

The $s i$-construction is abundantly found in apodoses of temporal phrases. In such instances, it indicates future events or situations that are temporarily preceded by other future activities, expressed in protases. It should be noted that although clearly future-oriented, the siconstruction sometimes preserves modal shades of meanings such as necessity, obligation, volition or possibility:

Sooma niy a naata, ì si taa lopitaanoo to tomorrow when he have.come, we SI go hospital to

"When he comes (once he has come) tomorrow, we will go to the hospital"

However, a similar context may frequently be interpreted in conditional terms. In such cases, the $s i$-construction indicates future certain-definite $(21 \mathrm{a}, \mathrm{b})$ or possible-probable $(21 \mathrm{c}, \mathrm{d})$ situations that logically (and frequently temporarily) depend on conditions introduced in protases. Yet again, the future value is accompanied by regular modal (real-factual $(21 \mathrm{a}, \mathrm{b})$ or real-counterfactual $(21 \mathrm{c}, \mathrm{d})$ undertones:

a. Niy ya kodoo soto, $n$ sitaa Banjul

if I money have, I SI go Banjul

"If I have money, I will certainly go to Banjul" 


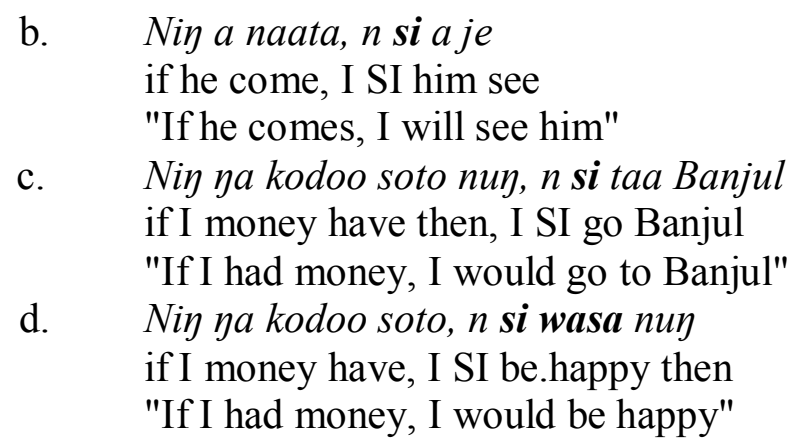

Also, the periphrastic chains with the verb noo can be found in apodotic environments:

\author{
Niy i lafita, i si n kendeyandi noo le! \\ if you want, you SI me cure can EMPH \\ "If you want, you will / you can / you will be able to cure me"
}

The examples found in apodoses presented thus far do not generally differ from the use of the si-construction in the main independent phrases introduced in section 2.1, which may be embraced under the labels of modality-futurity. More interesting are cases where the siconstruction appears in unreal counterfactual conditional chains referring to past events or situations. In such uses, it indicates that a given event could have occurred if a certain condition had been met. However, neither that condition nor the fact depending on it took place. It is also possible to use the $s i$-formation with a counterfactual and real sense in order to express hypothetical and imagined situations that, even though contrary to the present state of affairs, could be true (cf. examples (21c, d) above).

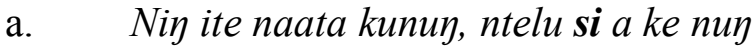
if you came yesterday, we SI it do then
"If you had come yesterday, we would have done it"
b. $\quad$ Niy nte ye motoo soto nuy, $n$ si taa Banjunu dimaasi tambilaa
if I did car have then, I SI go Banjul Sunday last
"If I had had the car, I would have gone to Banjul last Sunday"

\title{
2.4 Subordinate clauses
}

With great frequency, the $s i$-construction appears in subordinated clauses. It is employed both in asyndetic and syndetic clauses which are headed by determined conjunctions, in particular by $k o, f o$ and puru. In such cases, the si-construction approximates the category of a subjunctive, expressing the sense of finality and ideas of necessity, possibility or likelihood.

In an asyndetic environment, the construction is commonly employed in order to express various modal meanings (especially, the ideas of possibility (24) and obligation (25)) which are clearly analogous to the senses that are displayed in independent main phrases:

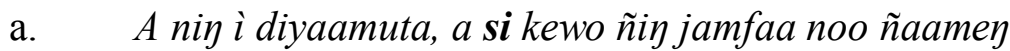

he with they talked, he SI man this betray can how

"They discussed how he could betray the man" (i.e. "They discussed how to betray the man") 
b. İ diyaamuta ñoo ye, ì si mey ke noo they talked each.other to, they SI what do can "They discussed what they could do" (i.e. "They discussed what to do")

c. $\quad$ Moolu be a ñinin kay, ì si kewo ñin faa ñaamey people are it seek on, they SI man this kill how "People were plotting how they could/might/would kill him" (i.e. "They were plotting how to kill him")

a. I lafita ì si a parendi minto le? you want we SI it prepare where EMPH "Where do you want, we should prepare it?" (i.e. "Where do you want us to prepare it?")

b. $\quad$ Ali si kuwolu ke moolu la, ali lafita, ì si mey ke ali la fanaa you shall things do people with, you want, they SI which do you at/with also "Do to others as you would like they should do to you" (i.e. "Do to others as you would like them to do to you")

With the lexeme ko "[saying] that", the si-construction introduces finality, coloured by an undertone of obligation and necessity:

a. A ye a fo n ye ko n se naa he did it say me to that I SI come "He told me [saying] that I should come / He told me to come"

b. A ye a daani ko a si kuluyo jamfandi tintoo la domandiy he did it ask that he SI boat put.outshore at/with little "He asked him [saying] that he should put out the boat a little way from the shore" (i.e. "He asked him to put out the boat a little way from the shore")

When headed by the conjunction fo "that, so that", the si-construction introduces the idea of purpose and finality (cf. in particular, examples (27a-d)), ${ }^{17}$ accompanied nevertheless by persistent modal tones of possibility-potentiality (could, may, might; cf. examples (28a, b)) and/or obligation (must, should; cf. examples (29a-c)):
a. İ ye a daani, fo a se duy konoto
they did him ask, so.that he SI enter inside come"
b. Dà a faa, fo keetaa si ke ̀̀ taa ti
Let.us him kill,so.that heritage SI be our possession EXIS ${ }^{18}$
"Let us kill him so that the heritage would be ours"
c. $\quad$ N hameta baake le, fo $n$ se domoroo domo
I want very.much EMPH, so.that I SI food eat
"I want very much to eat"

"They asked him to come inside" (or: "They asked him; he was compelled to

\footnotetext{
${ }^{17}$ It must be observed that even in these purpose clauses, the modal meaning of possibility and necessity is also available.

${ }^{18}$ The lexeme $t i$ is an existential particle that accompanies certain verbs with the meaning of "be" or "become" (e.g., $m u$ or $k e$ ). It will be glossed as EXIS.
} 
d. $\quad$ M be a ke la, fo moolu si njiyaa i la buyolu kono

I am it do to, so.that people SI me accommodate they of ${ }^{19}$ houses in

"I will do so that the people will accommodate me in their houses"

(28) a. I bambay fo ntel si a ke noo

yourself hurry.up so.that we SI it do can

"Hurry up so that we could do it"

b. Siimayo parendi ì ye, fo ì si a domo

dinner prepare we for, so.that we SI it eat

"Prepare dinner for us, so that we can eat"

(29) a. N lafita fo a si a ke

I want so.that he SI it do

"I want you to do it" ("I want you must do it")

b. N lafita fo a si a ke nuy

I want so.that he SI it do then

"I want you to have done it" ("I want you should have done it")

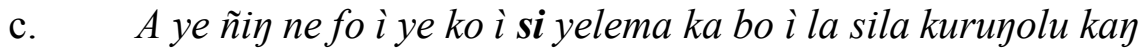

he did this EMPH say them to that they SI turn from you of way bad.ones on

"He told them to [that they should] turn from their evil ways"

Finally, when the subordinated clause is introduced by the conjunction puru "so that, in order to", the $s i$-construction almost invariably expresses aims and goals, functioning as a purposive category:

a. Da a faa puru n se a la buyo soto

I.did him kill so.that I SI he of house have

"I killed him to have his house / so that I would/could have his house"

b. Ì ye a daani puru a se duy konoto

they did him ask so.that he SI enter inside

"They asked him to come in"

In certain cases, however - which are most commonly limited to instances where the siconstruction is accompanied by the verb noo -, the idea of possibility and potentiality is also accessible:
Dà a faa puru ite si naa noo kotenke
we-did him kill so.that you SI come can again
"We killed him so that you could come again"

\section{Conclusion}

\subsection{Summing up the data}

In main independent clauses, the si-construction expresses future events almost invariably accompanied by modal tones of necessity and obligation. In the first person, it expresses desires and promises, obligation and necessity, as well as, permission and deliberation. In the second person, the si-construction commonly functions as an imperative. And in the third person, it

${ }^{19}$ The slot $i$ la (literally "they of") equals the English possessive pronouns of the third person plural "their". 
introduces the idea of future necessity, approximating the category of a jussive. In the same environments, the $s i$-construction may also introduce modal ideas of obligation and necessity situated in a past time frame (had to do or should have done). Still with the past temporal reference, this construction can function as a past future (was going to do), accompanied by modal shades of meaning. The si-construction is also found in a pure modal sense of epistemic possibility, with no apparent temporal (i.e. future) implications. Finally, it can denote present habitual and customary activities. Consequently, this group of values may be understood as a set-theoretic union of futurity and (especially, deontic) modality, combined rarely with the sphere of habituality. This profoundly modal nature of the $s i$-construction justifies its common use with the verb noo "be able, can, may". In these cases, the entire expression conveys various modal nuances (physical ability, mental capacity, root possibility, epistemic possibility, permission and volition), frequently bereaved of any future temporal connotations.

In temporal and conditional apodoses, the si-construction may approximate a modally tinted future (factual realis), a conditional (factual irrealis) or a past conditional (counterfactual irrealis).

In asyndetic subordinated clauses, the si-construction may be classified as a purposive subjunctive with important shades of possibility and necessity. When it is preceded by the conjunctions $k o$ and $f_{o}$, it indicates finality, necessity and possibility. And when headed by the lexeme puru, the form typically expresses finality and intentions. Nevertheless, it also admits certain modal readings in terms of possibility and potentiality, particularly when it is used with the verb noo.

\subsection{Final results}

The results of a detailed analysis of the semantic properties displayed by the si-construction generally coincides with the "traditional" - in the majority, superficial and incomplete descriptions and classifications as a future "tense" with strong modal implications, related to the concepts of possibility, ability, potentiality and obligation (direct and oblique commands; cf. Marbrair 1842; Rowlands 1959; Creissels 1983; Gamble 1987; and Colley 1995). However, the data also enable us to refine this definition and detect other - normally minimised or ignored - values offered by this construction.

First, the categorisation into four distinct classes which correspond to four different syntactic environments has enabled the author to impose some order and structure on a multitude of specific - yet clearly interconnected - values displayed by the si-construction. Second, it has been noticed that when employed with the first person singular and plural, the construction may express volition, permission and deliberation: these semantic domains are clearly distinct from other modal spheres identified in traditional studies. Third, as far as the idea of possibility is concerned, important distinctions between the sense of capacity-ability, root possibility and epistemic possibility have been made. Fourth, it has been observed that the si-construction may refer to past situations functioning as a past modal category and future in the past. Fifth, it has been demonstrated that the $s i$-construction can be used in conditional apodoses with the force of a counterfactual realis and irrealis, approximating the category of present and past conditionals. And sixth, in subordinated clauses headed by the conjunctions ko, fo and puru, the construction has been shown to introduce the idea of purpose and finality. On the contrary, in asyndetic depending clauses, the modal value is clearly predominant. 
Additionally, the compatibility of the si-construction with the idea of habituality and present durativity has been emphasised, which differentiates the present description with several traditional studies in which this fact has been underestimated or entirely ignored (cf. however, Creissels 1983 and Wilson 2000).

Although the evidence presented in this article is limited to Basse Mandinka, the conclusions drawn from it - and hence the description of the semantic potential of the si-construction - may successfully be applied to the normalised language, as well. It is highly probable that the siconstruction in Standard Mandinka displays the same values as those offered by its homologue employed in Basse and its neighborhoods. Of course, this claim - as plausible as it seems must be analysed in depth and substantiated by convincing examples. This suggested area of further analysis of the $s i$-construction constitutes one of the future research activities of the author.

\section{References}

Andrason, A. forthcoming (a). Introducción a la gramática del mandinka de la región de Basse.

Andrason, A. forthcoming (b). The meaning of the $Y E$ constructions in Basse Mandinka. A practical orthography of Gambian Mandinka. 1988. Banjul: WEC International.

Austin, J.L. 1962. How to do things with words. Oxford: Clarendon Press.

Bybee, J. 2010. Language, usage and cognition. Cambridge: Cambridge University Press.

Bybee, J., R. Perkins and W. Pagliuca. 1994. The evolution of grammar. Chicago: The University of Chicago Press.

Colley, E.S. 1995. Mandinka grammar manual. Banjul: Peace Corps The Gambia.

Creissels, D. 1983. Eléments de grammaire de la langue mandinka. Grenoble: ELLUG.

Dahl, Ö. (ed.) 2000. Tense and aspect in the languages of Europe. Berlin/New York: Mouton de Gruyter.

Dramé, M. 2003. Parlons mandinka. Paris: L'Harmattan.

Evans, V. and M. Green. 2006. Cognitive linguistics: An introduction. Edinburgh: Edinburgh University Press.

Gamble, D. 1987. Elementary Mandinka (Gambian Studies 20). San Francisco: Gamble.

Kambey Kotoo. 1998. Banjul: WEC International.

Kambey Kutoo. 1989. Banjul: WEC International.

Kastenholz, R. 1996. Sprachgeschichte im West-Mande: Methoden und Rekonstruktionen. Köln: Rüdiger Köppe Verlag.

Lewis, M.P. (ed.) 2009. Ethnologue: Languages of the world. Dallas: SIL International.

Macbrair, R.M. 1842. A grammar of the Mandingo language. London: The WesleyanMethodist Missionary Society.

Mandinka English dictionary. 1988. Banjul: WEC International.

Mandinka English dictionary. Revised edition. 1995. Banjul: WEC International.

Mandinka learning manual. 2002. Banjul: WEC International.

Nikiforidou, K. 2009. Constructional analysis. In F. Brisard, J-O. Östman and J. Verschueren (eds.) Grammar, meaning and pragmatics. Amsterdam/ Philadelphia: John Benjamins. pp. 16-32.

Palmer, F.R. 1986. Mood and modality. Cambridge: Cambridge University Press.

Portner, P. 2009. Modality. Oxford: Oxford University Press.

Rowlands, E.C. 1959. A grammar of Gambian Mandinka. London: SOAS.

Selections from the Writings of the Promised Messiah. 1988. Tilford: Islam International Publications LTD. 
Vydrine, V., T.G. Bergman and M. Benjamin. 2000. Mandé language family of West Africa: Location and genetic classification (SIL Electronic Survey Report). Dallas: SIL International.

Williamson, K. and R. Blench. 2000. Niger-Congo. In B. Heine and D. Nurse (eds.) African languages. Cambridge: Cambridge University Press. pp. 11-42.

Wilson, W. 2000. Creissels's Mandinka grammar. Journal of West African Languages 28(2): 109-124. 